\title{
Intellectual disability-brachydactyly-Pierre Robin syndrome
}

INSERM

\section{Source}

INSERM. (1999). Orphanet: an online rare disease and orphan drug data base. Intellectual disability-brachydactyly-Pierre Robin syndrome. ORPHA:364577

Intellectual disability-brachydactyly-Pierre Robin syndrome is a rare developmental defect during embryogenesis syndrome characterized by mild to moderate intellectual disability and phsychomotor delay, Robin sequence (incl. severe micrognathia and soft palate cleft) and distinct dysmorphic facial features (e.g. synophris, short palpebral fissures, hypertelorism, small, low-set, and posteriorly angulated ears, bulbous nose, long/flat philtrum, and bow-shaped upper lip). Skeletal anomalies, such as brachydactyly, clinodactyly, small hands and feet, and oral manifestations (e.g. bifid, short tongue, oligodontia) are also associated. Additional features reported include microcephaly, capillary hemangiomas on face and scalp, ventricular septal defect, corneal clouding, nystagmus and profound sensorineural deafness. 